\title{
An Analytical Expression of the Photoacoustic Signal for A Pulsed Laser with A Sinusoidal Radial Profile
}

\author{
Hakan Erkol ${ }^{1 *}$

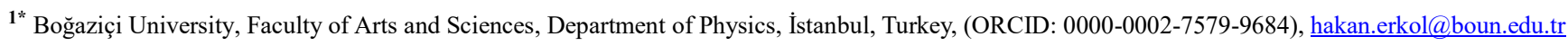

(First received 27 May 2021 and in final form 15 August 2021)

(DOI: 10.31590/ejosat.943805)

ATIF/REFERENCE: Erkol, H. (2021). An Analytical Expression of the Photoacoustic Signal for A Pulsed Laser with A Sinusoidal Radial Profile. European Journal of Science and Technology, (25), 727-735.

\begin{abstract}
Photoacoustic signal depends on several laser factors, particularly the pulse duration, energy, wavelength, beam-width and repetition rate of the pulsed laser. Although these dependencies are well tested through experiments, they can also be investigated via theoretical approaches for the research into photoacoustic signal generation in parallel to advances in laser technologies. In this study, the photoacustic signal is presented analytically by solving the photoacoustic wave equation for an optical absorber heated up by a pulsed laser. The spatial and temporal parts of the pulsed laser are modeled by a sampling (sinc) function and a Gaussian function, respectively. The radial profile obtained experimentally by using a spatial light modulator can be modeled accurately with a sampling function. Pulsed lasers can lead to nonlinear effects. This nonlinear mechanism has various advantageous for the photoacoustic imaging. These shortpulsed lasers have a close-to-sinusoidal variation in the central pulse region so that the spatial part of the laser is modeled by a sampling function in this work. For the photoacoustic wave, a detailed expression is obtained analytically in terms of the pulse duration and beamwidth. The photoacoustic signal is observed in terms of time for various detector positions. Moreover, a detailed analysis is conducted to obtain a correlation between the photoacoustic signal and the laser factors. Therefore, the resulting quantification of the physical laser factors can offer a useful theoretical guide for the applications of photoacoustics. The sampling modeling presented by this study can also be helpful for the understanding of the nonlinear mechanism in photoacoustics.
\end{abstract}

Keywords: Photoacoustics, Laser Factors, Spatiotemporal Profile.

\section{Sinüzoidal Uzaysal Kısma Sahip Kısa Atımlı Lazer Işığının Meydana Getirdiği Fotoakustik Sinyalin Analitik Olarak İfadesi}

Öz

Fotoakustik sinyal lazer 1şı̆̆ının atım süresi, enerjisi, dalgaboyu ve atım sıklığı gibi parametrelere bağlıdır. Bu parametrelerin fotoakustik sinyal üzerindeki etkileri deneyler ile test edilebilmektedir. Bununla birlikte bu etkiler teorik yaklaşımlar aracılığıyla lazer teknolojilerine paralel olarak araştırılabilir. Bu çalışmada, Fourier dönüşümü yöntemi kullanılarak fotoakustik dalga denkleminin çözümleri oldukça kısa dalga boylu lazer 1şığı tarafından uyarılmış küresel şekle sahip bir absorbe edici madde için elde edilmiştir. Darbeli lazerin uzaysal ve zamansal kısımları sırasıyla sinc ve Gaussian fonksiyonları ile modellenmiştir. Uzaysal 1şık modülatörü kullanılarak deneysel olarak elde edilmiş olan darbeli lazerin radyal kısmı sinc fonkyonu ile gerçeğe yakın olarak modellenmektedir. Ayrıca, darbeli lazerler lineer olmayan etkiler meydana getirirler. Lineer olmayan bu mekanizma fotoakustik görüntüleme tekniğinde bir takım avantajlara sahiptir. Darbeli lazerler merkezi atım bölgesinde sinüzoidal bir değişime sahiptir. Bundan dolayı bu çalışmada lazerin uzaysal kısmı sinc fonksiyonu ile tasvir edilmiştir. Lazer parametrelerini (atım süresi ve dalga genişliği) içeren ayrıntılı bir fotoakustik dalga (sinyal) ifadesi analitik olarak elde edilmiştir. Fotoakustik sinyal çeşitli dedektör pozisyonlarında (absorbe edici madde dışında) zamana bağlı olarak ifade edilmiştir. Ayrıca, yapılan analiz sonucunda fotoakustik sinyal ile lazer parametreleri arasında bir korelasyon olduğu saptanmıştır. Sonuç olarak lazer parametrelerinin nicel olarak belirlenmesine imkan veren bu çalışma fotoakustik alanındaki uygulamalar için faydalı olabilir.

Anahtar Kelimeler: Fotoakustik, Lazer Parametreleri, Uzaysal-Zamansal Profil.

*Corresponding Author: hakan.erkol@boun.edu.tr 


\section{Introduction}

Photoacoustic effect (which is also known as optoacoustic effect) was first described by Alexander Graham Bell (Bell 1880). Pressure waves are generated because of the change in thermal energy in a very short time (thermal expansion) if a very short pulsed laser is sent into a turbid medium. Photoacoustic Imaging (PAI) utilizing the photon absorption to create a contrast between an absorbing medium and a non-absorbing medium is based on this phenomenon (Zhang et al. 2009). The photoacoustic pressure waves propagating through medium are acquired by ultrasonic transducers. In photoacoustic effect, the pulse duration has to be shorter than the thermal time and stress confinement time (Wang 2008). Photoacoustic imaging can be implemented as a tomographic imaging as well as a microscopic imaging (Zhang et al. 2009).

Photoacoustic imaging has a broad range of applications in biomedical sciences (Hutchins and Tam 1986; Tam 1986; Ripol and Ntziachristos 2005; Beard 2011; Lin 2018). Two main advantages of this imaging technique are the utilization of high optical contrast and high ultrasonic resolution so that this technique not only resolves cells but gives structural information as well (Wang 2004). Besides, it is safe for in vivo studies since it does not have an ionizing absorption mechanism. Therefore, photoacoustic imaging is a favourable imaging method for biomedical optics due to the aforementioned advantages ( $\mathrm{Xu}$ and Wang 2006; Wang and Wu 2007).

Laser factors (such as beam-width, pulse repetition frequency, pulse duration, laser power) determine the resolution and contrast of photoacoustic imaging. Hence, an analytic expression for the pressure waves, which has explicit dependencies of the laser factors, can be very useful to determine the behavior of photoacoustic signals accurately for various imaging purposes. Photoacoustic wave equation has been solved analytically by modeling the source term (spatial and temporal parts of the pulsed laser) of the equation with the Dirac delta, Rectangular and Gaussian functions (Wang and $\mathrm{Wu}$ 2007; Diebold, Shan, and Khan 1991; Diebold and Westervelt 1988). Wang presented solutions to the photoacoustic wave equation for the spatial and temporal profiles which are both described by the Dirac delta functions since the interaction of the light with the medium is very localized (in both space and time) (Wang and $\mathrm{Wu}$ 2007). Even though the solution is very convenient for some applications of photoacoustics, it does not show any explicit dependencies of some of the laser factors (such as pulse duration or beam-width) on the photoacoustic signal.

Diebold et al. (1988) obtained not only solutions to the photoacoustic wave equation but also introduced theorems for an excitation resulted from a short pulsed laser incident upon a liquid. Diebold et al. (1988) studied the photoacouctic wave generation resulted from a spherical absorber. They presented photoacoustic wave expressions in the frequency and time domains for a pulsed laser approximated by a delta function. Lai et al. (2020) also derived a theory for an optoacoustic method utilizing short pulsed lasers for a weakly absorbing medium. They presented some analytical and numerical solutions for a Gaussian spatiotemporal profiles (both spatial and temporal parts are modeled by Gaussian functions). Their results are based on the far field approximation. Bai et al. (2018) also extended the photoacoustic theory to investigate the effects of a stratified atmosphere and a gravitational field on pressure waves. They studied some properties of pressure waves due to the optical excitation.

In literature, the photoacoustic wave generation was generally described by modeling the source term of the wave equation (the product of the radial part and the temporal part of the laser) by Gaussian and/or delta functions and the solution to the wave equation was presented based on some analytical methods (such as Laplace Transform) (Calasso, Craig, and Diebold 2001; Hoelen et al. 1998; Sigrist and Kneubühl 1978; Kozhushko et al. 2004). Tabaru et al. (2018) analyzed frequency domain solutions to the acoustic wave equation, which is very useful in acoustic sensor design. In their studies, the temporal and the spatial profiles were represented by the Dirac delta and Gaussian functions (Tabaru et al. 2019; Tabaru, Hayber, Saracoglu 2018). In another study, Uluc et al. (2018) described the photoacoustic signal resulted from red blood cells moving in a microfluidic channel and presented a transport model for the characterization of red blood cells.

In photoacoustics, the radial and the temporal parts of the pulsed laser are usually described by the Dirac delta, Rectangular, and Gaussian functions because the interaction of the pulsed laser with the medium is very short ranged in both space and time. The explicit dependencies of some laser factors do not appear in the solution for the former two models. Especially for the delta function approach, there are no any explicit dependencies of the factors in the photoacoustic wave expression while there is a beam-width dependency in the wave expression when the spatial part of the laser is approximated by the rectangular function. In some cases (if the spatial profile is treated as uniform), it can be practical for the calculation point of view. Still, this model is not quite realistic. Nevertheless, the Gaussian model enables to observe explicit dependencies of the beam-width and pulse duration on the photoacoustic signal emitted from the absorber. However, the solutions for the Gaussian spatial and temporal profiles are mainly obtained for various approximations such as the far-field approximation.

In this study, the photoacoustic wave equation is solved analytically for a spherical absorber. The temporal part of the pulsed laser is modeled with a Gaussian function, which leads to an explicit pulse duration dependency on the signal. The spatial part of the laser is described by a sampling (sinc) function which enables to observe a direct dependency of the beam-width on the signal. For very small values of the beam-width, the profile behaves like a Gaussian (and also like a delta function). At the same time, its behavior becomes very similar to the rectangular profile when the beam-width is large enough provided that it does not violate the thermal expansion condition. This sampling modeling can also be used to describe the radial profile obtained experimentally resulted from a spatial light modulator. First of all, an exact and detailed frequency domain solution is obtained by utilizing the Fourier transform and the Greens' function methods. Later, the corresponding time domain solution is found by using the inverse Fourier transform. The only assumption is that the solution has a spherical symmetry (it is independent from the azimuthal angle, which is quite realistic.). The applicability of this method presented in this study is analyzed by first obtaining the photoacoustic waves and then by plotting the signal versus time for various locations. The results of this method are also compared with some other work's (delta function approach) results in some limit case (when the beam-width is very small). This comparison shows that the results obtained by the two methods are almost in a perfect agreement. The effects of the laser factors; beam-width 
and pulse duration, on the photoacoustic wave are investigated as well.

The nonlinear mechanisms in the field of photoacoustics present various advantages, such as enhancement of imaging contrast, measurement of temperature of tissue, acquiring superresolution images, and obtaining important physical parameters (Gao et al. 2021). Nanosecond (also picosecond) pulsed lasers are employed as excitation sources to produce nonlinear effects in tissue. These types of laser sources have a close-to-sinusoidal variation in the central pulse region which can be modeled by a sampling function (Gao et al. 2021; Audo et al. 2017; Gusev and Chigarev 2010). In this work, a sampling approach based on a simple observation of typical excitation sources is presented. A correlation between the photoacoustic signal and the laser factors by using the Greens' function method is obtained. Analytic expressions of the signal for the potential applications of these types of laser sources can be helpful for the understanding of this nonlinear mechanism in this field. Therefore, this sampling function modeling can be useful in photoacoustics.

\section{Material and Method}

The photoacoustic pressure wave is described by the following differential equation.

$$
\left(\nabla^{2}-\frac{1}{v^{2}} \frac{\partial^{2}}{\partial t^{2}}\right) p(\mathbf{r}, t)=-\frac{\beta}{\kappa v^{2}} \frac{\partial^{2} T(\mathbf{r}, t)}{\partial t^{2}}
$$

Where $v, p(r, t), \beta, \kappa$, and $T(r, t)$ are the speed of sound, the photoacoustic pressure wave, the thermal coefficient of volume expansion, isothermal compressibility, and the increase in temperature at position $r$ and time $t$, respectively (Wang 2008). The left hand side of equation (1) represents the propagation of the pressure wave while the right hand side of equation (1) represents the source associated with the pulsed laser. If the pulsed laser is sufficiently short, the thermal equation has the following form

$$
\rho C_{V} \frac{\partial T(\mathbf{r}, t)}{\partial t}=H(\mathbf{r}, t) .
$$

Here, $H$ is defined as the heating function which is the thermal energy produced by the absorption of the laser light per unit volume and per unit time (the product of the optical absorption coefficient $\mu_{a}$ and the light fluence $\left.F, H=\mu_{a} F\right), \rho$ and $C_{V}$ are the density and the specific heat capacity at constant volume, respectively (Wang 2008; Wang and Wu 2007).

In the photoacoustic effect, both the acoustic confinement time and the thermal confinement time are longer than the pulse duration of the laser. Hence, the laser pulse has to be sufficiently short. Therefore, the photoacoustic wave equation takes the following form

$$
\left(\nabla^{2}-\frac{1}{v^{2}} \frac{\partial^{2}}{\partial t^{2}}\right) p(\mathbf{r}, t)=-\frac{\beta}{C_{P}} \frac{\partial H(\mathbf{r}, t)}{\partial t} .
$$

The source term of equation (3) is described by

$$
S(\mathbf{r}, t) \equiv-\frac{\beta}{C_{P}} \frac{\partial H(\mathbf{r}, t)}{\partial t}
$$

where the heating function $H(r, t)$ is modeled as a product of the spatial $A(r)$ and the temporal $H(t)$ parts

$$
H(\mathbf{r}, t)=A(\mathbf{r}) H(t) .
$$

If the pulsed laser is quite confined in time, its temporal profile can be modeled by a Gaussian function

$$
H(t)=\frac{\exp \left(-\frac{t^{2}}{2 \tau^{2}}\right)}{\sqrt{2 \pi \tau^{2}}} .
$$

Here, $\tau$ is the pulse duration. If the stress confinement condition is met (i.e., the stress relaxation time is much greater than the pulse duration), the increase in the initial pressure, $\mathrm{p}_{0}(\mathrm{r})$, immediately after the laser incident on the absorber, is given by (Wang 2008; Wang and Wu 2007)

$$
p_{0}(\mathbf{r})=\frac{\beta T(\mathbf{r})}{\kappa}
$$

Here, the increase in temperature can be described by

$$
T(\mathbf{r})=\frac{A(\mathbf{r})}{\rho C_{V}}
$$

if all of the energy of the laser pulse is transformed into the thermal energy and the nonthermal relaxation is ignored. Incorporating equations (7) and (8) and writing

$$
\kappa=\frac{C_{P}}{\rho v^{2} C_{V}}
$$

yields

$$
A(\mathbf{r})=\frac{p_{0}(\mathbf{r})}{v^{2}} \frac{C_{P}}{\beta}
$$

Writing equation (10) into equation (5) gives

$$
\begin{aligned}
S(\mathbf{r}, t) & =-\frac{p_{0}(\mathbf{r})}{v^{2}} \frac{\partial}{\partial t}\left[\frac{\exp \left(-\frac{t^{2}}{2 \tau^{2}}\right)}{\sqrt{2 \pi \tau^{2}}}\right] \\
& =\frac{1}{\sqrt{2 \pi} \tau^{3}} \frac{p_{0}(\mathbf{r})}{v^{2}} t \exp \left(-\frac{t^{2}}{2 \tau^{2}}\right) .
\end{aligned}
$$

Taking the Fourier transform of the source $S(r, t)$ leads to

$$
\begin{aligned}
\tilde{S}(\mathbf{r}, \omega) & =\frac{1}{\sqrt{2 \pi} \tau^{3}} \frac{p_{0}(\mathbf{r})}{v^{2}} \int_{-\infty}^{\infty} t \exp \left(-\frac{t^{2}}{2 \tau^{2}}\right) \exp (i \omega t) d t \\
& =\frac{i}{\sqrt{2 \pi}} \frac{p_{0}(\mathbf{r})}{v^{2}} \omega \exp \left(-\frac{\tau^{2} \omega^{2}}{2}\right) .
\end{aligned}
$$

Therefore, photoacoustic wave equation (1) is written as 


$$
\nabla^{2} \tilde{p}(\mathbf{r}, \omega)+\frac{\omega^{2}}{v^{2}} \tilde{p}(\mathbf{r}, \omega)=i \frac{p_{0}(\mathbf{r})}{v^{2}} \omega \exp \left(-\frac{\tau^{2} \omega^{2}}{2}\right)
$$

in the frequency domain by utilizing the following Fourier transform:

$$
p(\mathbf{r}, t)=\frac{1}{\sqrt{2 \pi}} \int_{-\infty}^{\infty} \tilde{p}(\mathbf{r}, \omega) \exp (-i \omega t) d \omega .
$$

In unbounded space, equation (13) has the following Greens' function (Morse and Feshbach 1953)

$$
\tilde{G}\left(\mathbf{r}, \mathbf{r}^{\prime} ; \omega\right)=-\frac{1}{4 \pi\left|\mathbf{r}-\mathbf{r}^{\prime}\right|} \exp \left(i \frac{\omega}{v}\left|\mathbf{r}-\mathbf{r}^{\prime}\right|\right) .
$$

Evaluation of the following integral

$$
\tilde{p}(\mathbf{r}, \omega)=\int \tilde{G}\left(\mathbf{r}, \mathbf{r}^{\prime} ; \omega\right) \tilde{S}\left(\mathbf{r}^{\prime} ; \omega\right) d^{3} r^{\prime}
$$

yields the photoacoustic wave in the frequency domain. Substituting equations (12) (the source term) and (15) (the Greens' function) into equation (16) leads to

$$
\begin{aligned}
\tilde{p}(\mathbf{r}, \omega)= & -\frac{i}{4 \pi} \frac{\omega}{v^{2}} \exp \left(-\frac{\tau^{2} \omega^{2}}{2}\right) \\
& \int p_{0}\left(r^{\prime}\right) \frac{\exp \left(i \frac{\omega}{v}\left|\mathbf{r}-\mathbf{r}^{\prime}\right|\right)}{\left|\mathbf{r}-\mathbf{r}^{\prime}\right|} d^{3} r^{\prime} .
\end{aligned}
$$

Now, the initial pressure generated inside a spherical-like absorber due to the pulsed laser irradiation is modeled by the following expression

$$
p_{0}(r)=p_{0} U(r) U(-r+R)
$$

where $U$ denotes the Heaviside step function. The radial absorption profile is the first time described by a sampling function, which is a more realistic and comprehensive approach than the models mainly used in the literature such as the Dirac delta and uniform radial profile models

$$
p_{0}(r)=p_{0} \operatorname{sinc}\left(\frac{r}{\sigma}\right) U(r) U(-r+R)
$$

where $\operatorname{sinc}(\mathrm{x})=\sin (x) / x$, and $\sigma$ is the beam-width of the laser. The solution in the frequency domain can be found by substituting equations (12), (15), and (19) into equation (16)

$$
\begin{aligned}
\tilde{p}(r, \omega)= & -\frac{i p_{0} \omega}{4 \pi v^{2}} \exp \left(-\frac{\tau^{2} \omega^{2}}{2}\right) \\
& \times \int_{0}^{2 \pi} d \phi^{\prime} \int_{0}^{R} \operatorname{sinc}\left(\frac{r}{\sigma}\right)\left(r^{\prime}\right)^{2} d r^{\prime} \\
& \times \int_{-1}^{1} \frac{\exp \left(i \frac{\omega}{v}\left|\mathbf{r}-\mathbf{r}^{\prime}\right|\right)}{\left|\mathbf{r}-\mathbf{r}^{\prime}\right|} d \eta^{\prime}
\end{aligned}
$$

$\eta=\cos \theta$. The calculation of the integral over $\eta^{\prime}$ on the right hand side of equation (20) gives

$$
\begin{array}{r}
\int_{-1}^{1} \frac{\exp \left[i \frac{\omega}{v}\left(r^{2}+r^{\prime 2}-2 r r^{\prime} \eta^{\prime}\right)^{1 / 2}\right]}{\left(r^{2}+r^{\prime 2}-2 r r^{\prime} \eta^{\prime}\right)^{1 / 2}} d \eta^{\prime}= \\
-\frac{1}{i r r^{\prime} \frac{\omega}{v}}\left\{\exp \left[i \frac{\omega}{v}\left(r-r^{\prime}\right)\right]-\exp \left[i \frac{\omega}{v}\left(r+r^{\prime}\right)\right]\right\} .
\end{array}
$$

The frequency domain solution is obtained by writing the result of the integral in equation (21) into equation (20)

$$
\begin{array}{r}
\tilde{p}(r, \omega)=\frac{p_{0}}{2 \pi} \frac{1}{v r} \exp \left[-\frac{\tau^{2} \omega^{2}}{2}\right]\left\{\int_{0}^{R} r^{\prime} \operatorname{sinc}\left(\frac{r^{\prime}}{\sigma}\right)\right. \\
\left.\quad \times\left[\exp \left[i \frac{\omega}{v}\left(r-r^{\prime}\right)\right]-\exp \left[i \frac{\omega}{v}\left(r+r^{\prime}\right)\right]\right] d r^{\prime}\right\} .
\end{array}
$$

Here, $r>R$ or $r>r^{\prime}$ ( $r$ can be considered as a detector position which is outside the photoacoustic absorber). Therefore, the solution becomes

$$
\begin{aligned}
\tilde{p}(r, \omega)= & \frac{p_{0}}{2 \pi r} \frac{\sigma^{2}}{\left(v^{2}-\sigma^{2} \omega^{2}\right)} \\
& \times \exp \left[-\frac{\tau^{2} \omega^{2}}{2}+\frac{i \omega(r-R)}{v}\right] \\
& \times\left\{v \cos \left(\frac{R}{\sigma}\right)\left[-1+\exp \left(\frac{2 i R \omega}{v}\right)\right]-\right. \\
& \left.i \sigma \omega \sin \left(\frac{R}{\sigma}\right)\left[1+\exp \left(\frac{2 i R \omega}{v}\right)\right]\right\}
\end{aligned}
$$

By taking the inverse Fourier transform of equation (23), the time domain solution can be obtained as follows

$$
\begin{aligned}
p(r, t) & =\frac{p_{0}}{2 \sqrt{2 \pi}} \frac{1}{v r} \\
& \times \int_{0}^{R} r^{\prime} \operatorname{sinc}\left(\frac{r^{\prime}}{\sigma}\right) \\
& \times \int_{-\infty}^{\infty}\left\{\exp \left[-\frac{\tau^{2} \omega^{2}}{2}+i \omega\left(\frac{r-r^{\prime}}{v}-t\right)\right]\right. \\
& \left.-\exp \left[-\frac{\tau^{2} \omega^{2}}{2}+i \omega\left(\frac{r+r^{\prime}}{v}-t\right)\right]\right\} d \omega d r^{\prime} .
\end{aligned}
$$

The evaluation of the following two integrals in equation (24) yields

$$
\begin{array}{r}
\int_{-\infty}^{\infty} \exp \left[-\frac{\tau^{2} \omega^{2}}{2}+i \omega\left(\frac{r-r^{\prime}}{v}-t\right)\right] d \omega= \\
\frac{\sqrt{2 \pi}}{\tau} \exp \left[-\frac{\left(\frac{r-r^{\prime}}{v}-t\right)^{2}}{2 \tau^{2}}\right]
\end{array}
$$

and 


$$
\begin{array}{r}
\int_{-\infty}^{\infty} \exp \left[-\frac{\tau^{2} \omega^{2}}{2}+i \omega\left(\frac{r+r^{\prime}}{v}-t\right)\right] d \omega= \\
\frac{\sqrt{2 \pi}}{\tau} \exp \left[-\frac{\left(\frac{r+r^{\prime}}{v}-t\right)^{2}}{2 \tau^{2}}\right] .
\end{array}
$$

Writing equations (25) and (26) into equation (24) gives

$$
\begin{aligned}
& p(r, t)=\frac{p_{0}}{2} \frac{1}{v r \tau} \int_{0}^{R} r^{\prime} \operatorname{sinc}\left(\frac{r^{\prime}}{\sigma}\right) \\
& \times\left\{\exp \left[-\frac{\left(\frac{r-r^{\prime}}{v}-t\right)^{2}}{2 \sigma^{2}}\right] \exp \left[-\frac{\left(\frac{r+r^{\prime}}{v}-t\right)^{2}}{2 \sigma^{2}}\right]\right\} d r^{\prime}
\end{aligned}
$$

for $r>R$.

Substituting the following results

$$
\begin{array}{r}
\int_{0}^{R} r^{\prime} \operatorname{sinc}\left(\frac{r^{\prime}}{\sigma}\right) \exp \left[-\frac{\left(\frac{r-r^{\prime}}{v}-t\right)^{2}}{2 \tau^{2}}\right] d r^{\prime}= \\
\frac{1}{2} i \sqrt{\frac{\pi}{2}} \sigma \tau v \exp \left[-\frac{\tau^{2} v^{2}+2 i \sigma(r+v t)}{2 \sigma^{2}}\right] \\
\times\left\{e ^ { \frac { 2 i r } { \sigma } } \left[\operatorname{erf}\left(\frac{-r \sigma+v\left(\sigma t-i \tau^{2} v\right)}{\sqrt{2} \sigma \tau v}\right)-\right.\right. \\
\left.\operatorname{erf}\left(\frac{-r \sigma+R \sigma+\sigma v t-i \tau^{2} v^{2}}{\sqrt{2} \sigma \tau v}\right)\right] \\
+e^{\frac{2 i v t}{\sigma}}\left[\operatorname{erf}\left(\frac{-r \sigma+R \sigma+\sigma v t+i \tau^{2} v^{2}}{\sqrt{2} \sigma \tau v}\right)-\right. \\
\left.\left.\operatorname{erf}\left(\frac{-r \sigma+v\left(\sigma t+i \tau^{2} v\right)}{\sqrt{2} \sigma \tau v}\right)\right]\right\}
\end{array}
$$

and

$$
\begin{array}{r}
\int_{0}^{R} r^{\prime} \operatorname{sinc}\left(\frac{r^{\prime}}{\sigma}\right) \exp \left[-\frac{\left(\frac{r+r^{\prime}}{v}-t\right)^{2}}{2 \tau^{2}}\right] d r^{\prime}= \\
\frac{1}{2} i \sqrt{\frac{\pi}{2}} \sigma \tau v \exp \left[-\frac{\tau^{2} v^{2}+2 i \sigma(r+v t)}{2 \sigma^{2}}\right] \\
\times\left\{-1+\operatorname{erf}\left(\frac{r \sigma+v\left(\sigma t-i \tau^{2} v\right)}{\sqrt{2} \sigma \tau v}\right)+\right. \\
\operatorname{erfc}\left(\frac{\sigma(r-R+v t)-i \tau^{2} v^{2}}{\sqrt{2} \sigma \tau v}\right) \\
+e^{\frac{2 i r}{\sigma}}\left[\operatorname{erf}\left(\frac{r \sigma-\sigma(R+v t)+i \tau^{2} v^{2}}{\sqrt{2} \sigma \tau v}\right)-\right. \\
\left.\left.\operatorname{erf}\left(\frac{\sigma(r+R-v t)+i \tau^{2} v^{2}}{\sqrt{2} \sigma \tau v}\right)\right]\right\}
\end{array}
$$

into equation (24) (Here, erf and erfc are the error and the complementary error functions, respectively.), the time domain solution to the photoacoustic wave equation is obtained as

$$
\begin{gathered}
p(r, t)=i p_{0} \sqrt{\frac{\pi}{2}} \frac{\sigma}{4 r} \exp \left[-\frac{\tau^{2} v^{2}+2 i \sigma(r+v t)}{2 \sigma^{2}}\right] \\
\times\left\{e ^ { \frac { 2 i v t } { \sigma } } \left[\operatorname{erf}\left(\frac{\sigma(r+R-v t)-i \tau^{2} v^{2}}{\sqrt{2} \sigma \tau v}\right)-\right.\right. \\
\left.\quad \operatorname{erf}\left(\frac{r \sigma-\sigma(R+v t)-i \tau^{2} v^{2}}{\sqrt{2} \sigma \tau v}\right)\right] \\
+e^{\frac{2 i r}{\sigma}}\left[\operatorname{erf}\left(\frac{r \sigma-\sigma(R+v t)+i \tau^{2} v^{2}}{\sqrt{2} \sigma \tau v}\right)-\right. \\
\left.\left.\operatorname{erf}\left(\frac{\sigma(r+R-v t)+i \tau^{2} v^{2}}{\sqrt{2} \sigma \tau v}\right)\right]\right\} .
\end{gathered}
$$

Depending on the propagation time, the following cases can occur for the absorber of radius $R$ heated by a pulsed laser (when $\mathrm{r}>\mathrm{R}$ ) (Wang and $\mathrm{Wu}$ 2007). If either $r-R>v$ tor $r+R<v t, p(r, t)$ becomes zero since the absorber does not cross with the spherical shell of radius $v t$ centered at the detector position $r$. On the other hand, if $r-R<v t<r+R$, the spherical object meets the spherical shell of radius $v t$. Hence, the photoacoustic wave is presented by equation (30). Therefore, by taking into consideration the aforementioned cases and utilizing the Heaviside step function, $U(x)$, the solution takes its final form in time domain

$$
\begin{aligned}
& p(r, t)= i p_{0} \sqrt{\frac{\pi}{2}} \frac{\sigma}{4 r} \exp \left[-\frac{\tau^{2} v^{2}+2 i \sigma(r+v t)}{2 \sigma^{2}}\right] \\
& \times\left\{e ^ { \frac { 2 i v t } { \sigma } } \left[\operatorname{erf}\left(\frac{\sigma(r+R-v t)-i \tau^{2} v^{2}}{\sqrt{2} \sigma \tau v}\right)-\right.\right. \\
&\left.\operatorname{erf}\left(\frac{r \sigma-\sigma(R+v t)-i \tau^{2} v^{2}}{\sqrt{2} \sigma \tau v}\right)\right] \\
&+e^{\frac{2 i r}{\sigma}}\left[\operatorname{erf}\left(\frac{r \sigma-\sigma(R+v t)+i \tau^{2} v^{2}}{\sqrt{2} \sigma \tau v}\right)-\right. \\
&\left.\left.\operatorname{erf}\left(\frac{\sigma(r+R-v t)+i \tau^{2} v^{2}}{\sqrt{2} \sigma \tau v}\right)\right]\right\} .
\end{aligned}
$$


$\times U(r-|R-v t|) U(-r+R+v t)$.

\section{Results and Discussion}

In this part, the feasibility of the method is analyzed. First of all, the normalized spectral amplitudes of the photoacoustic waves (the solutions in the frequency domain, $\tilde{\mathrm{p}}(\mathrm{r}, \omega) / \mathrm{p}_{0}$ ) are illustrated in figure 1 for beam-width value $\tau=50 \mu \mathrm{m}$, pulse duration values $\tau=1,5$ and $15 \mathrm{~ns}$ at $\mathrm{r}=100 \mu \mathrm{m}$, respectively. The speed of the wave, the absorber's radius, and the beam-width are chosen as $v$ ( $v_{s}$, speed of sound in water) $1480 \mathrm{~m} / \mathrm{s}, \mathrm{R}=75 \mu \mathrm{m}$, and $\tau=50 \mu \mathrm{m}$, respectively for biomedical applications (Wang 2008; Wang et al. 2003; Wang et al. 2004). The signal decreases with the pulse duration. These results are in a good accordance with the literature (Tabaru et al. 2019; Tabaru, Hayber, Saracoglu 2018). The change in the normalized photoacoustic pressure waves $\left(\mathrm{p} / \mathrm{p}_{0}\right)$ with respect to normalized time $\left(\mathrm{v}_{\mathrm{s}} \mathrm{t} / \mathrm{R}\right)$ is also observed for different positions as shown in figure 2 . The photoacoustic waves are obtained at radial positions $r=100,150,200 \mu \mathrm{m}$, respectively where the pulse duration of the laser is taken as $\tau=5 \mathrm{~ns}$ (Uluc et al. 2018) in figure 2. Similar results are also presented for the applications of ultra-short laser pulses in figure 3 where the pulse duration is taken as $\tau=5$ fs. Figure 3 shows that the signal decreases with the position as it increases with the beam-width.

Laser pulse results in an initial pressure $p_{0}$ via thermal expansion and this initial pressure is constant throughout the spherical object. Each spherical pressure wave is split into two waves which have the same amplitude. In figure 2, the diverging spherical wave travels outward which is on the positive y axis whereas the converging spherical wave travels inwards which is on the negative $y$ axis. The comparison of the photoacoustic waves in figure 2 shows that the amplitude of the normalized signal decreases with the radial position outside the object and the behavior of the photoacoustic signal as a function of time indicates a good agreement with the literature (Wang 2008).

The results obtained by the method presented in this study are compared with the results of another approach (Wang 2008) as can be shown in figure 4. In that approach (Wang 2008), the temporal and the spatial parts of the source (pulsed laser) are modeled by delta functions. The source is treated as a point source since the interaction is very sudden and local in space so that it can be approximated by delta functions. As the beam-width becomes very small (compared with the radius of the absorber), the spatial profile described by the sampling function behaves like a delta function. The signal was presented by the following expression in Wang's work (Wang 2008)

$$
\begin{aligned}
p(r, t)= & p_{0}[U(R-v t-r) \\
& \left.+\frac{r-v t}{2 r} U(r-|R-v t|) U(R+v t-r)\right]
\end{aligned}
$$

where $U$ is the Heaviside step function. Therefore, the results obtained by equation (31) (this study) are in a very good accordance with the results obtained by equation (32) (Wang's work) as can be seen in figure 4 . In figure 5 , the behaviour of the signal is observed in terms of time for three different beam-width values $\sigma=50,75$ and $100 \mu \mathrm{m}$ where the position is $r=100 \mu \mathrm{m}$ and the pulse duration is $\tau=5 \mathrm{~ns}$. As can be seen in figure 5, the signal increases with the beam-width at any instant. This effect e-ISSN: 2148-2683 can also been seen clearly in figure 6 which illustrates the change in the amplitude of the photoacoustic signal in terms of the beamwidth for various pulse duration values $\tau=1,5$, and $10 \mathrm{~ns}$ at $r=$ $100 \mu \mathrm{m}$. The signal diminishes as the beam-width decreases since the behaviour of the sampling function describing the radial profile becomes very similar to one of the delta function so that there will not be any explicit dependence of the beam-width on the signal. Moreover, the signal reaches a saturation value when the beam-width is grater than the radius of the absorber. Figure 7 illustrates how the pulse duration affects the photoacoustic signal for various beam-width values $\sigma=10,50$ and $75 \mu \mathrm{m}$ at $r=100$ $\mu \mathrm{m}$. The signal decreases as the pulse duration increases because the power of the laser is a decreasing function of the pulse duration. It is also important to note that the signal disappears for large values of the pulse duration since the pulse duration becomes longer than stress confinement time and/or thermal confinement time. As a result of this, the propagation of the wave cannot be described by the photoacoustic wave equation. In other words, the stress and thermal confinement conditions are no longer met, and hence the photoacoustic wave equation is not valid anymore.

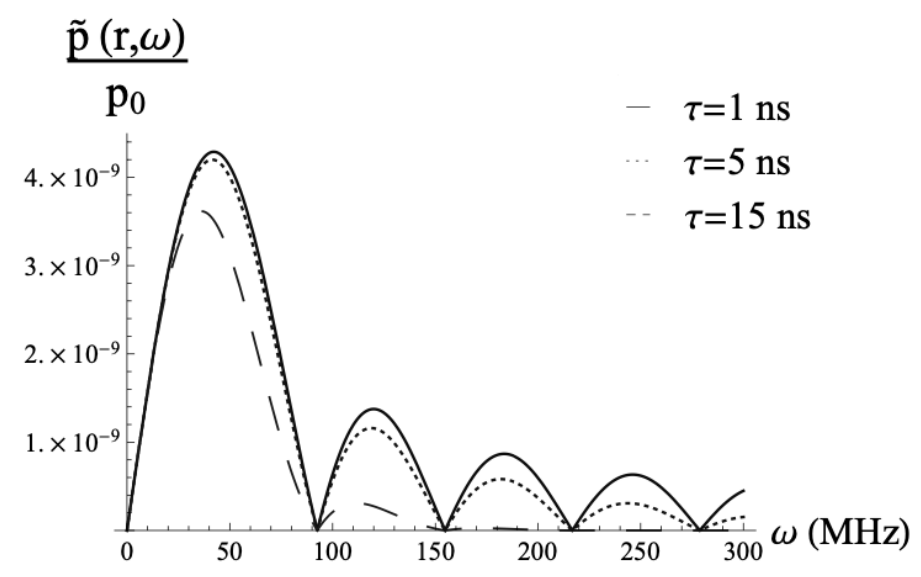

Figure 1. Normalized photoacoustic spectral amplitude $\tilde{p}(r, \omega) / p_{0}$ vs. frequency $\omega$ values of $\tau=1,5$ and $15 \mathrm{~ns}$ at $r=100 \mu \mathrm{m}$, respectively where the radius of the absorber $R=75 \mu \mathrm{m}$ and the beam-width $\tau=50 \mu \mathrm{m}$. 


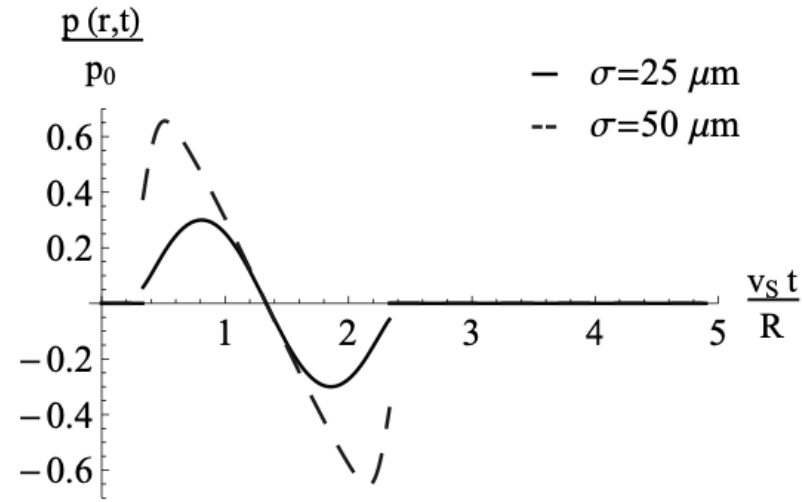

(a)

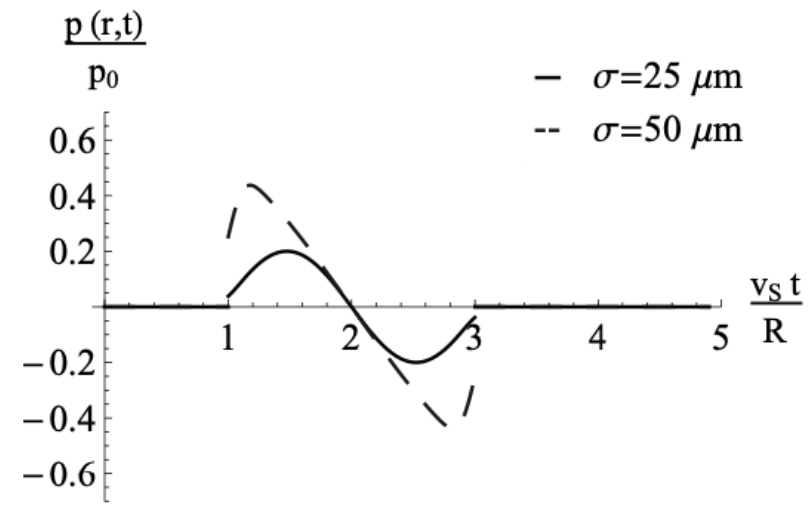

(b)

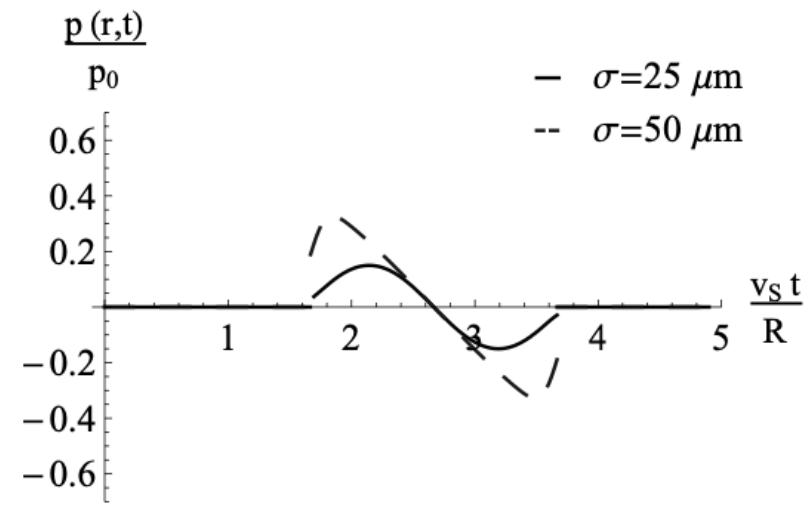

(c)

Figure 2. Normalized photoacoustic signal $p(r, t) / p_{0} v s$. normalized time $v_{s} t / R$ for beam-width values of $\sigma=25$ and 50 um at (a) $r=100 \mu \mathrm{m}$, (b) $r=150 \mu \mathrm{m}$, and (c) $r=200 \mu \mathrm{m}$, respectively where the radius of the absorber $R=75 \mu \mathrm{m}$ and pulse duration $\tau=5 \mathrm{~ns}$.

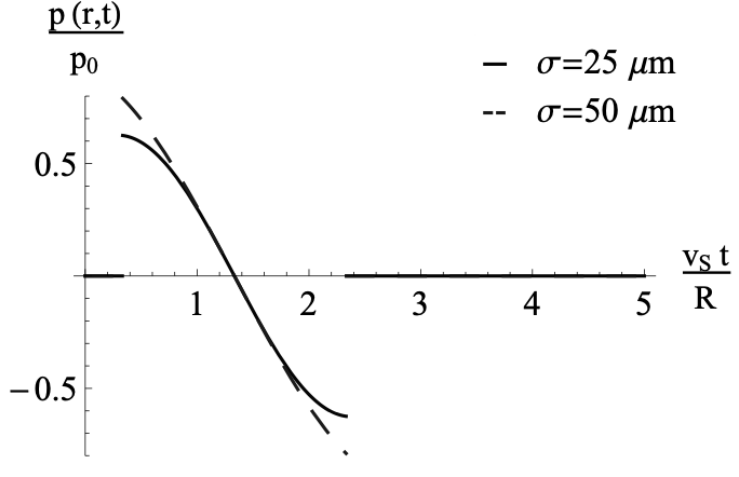

(a)

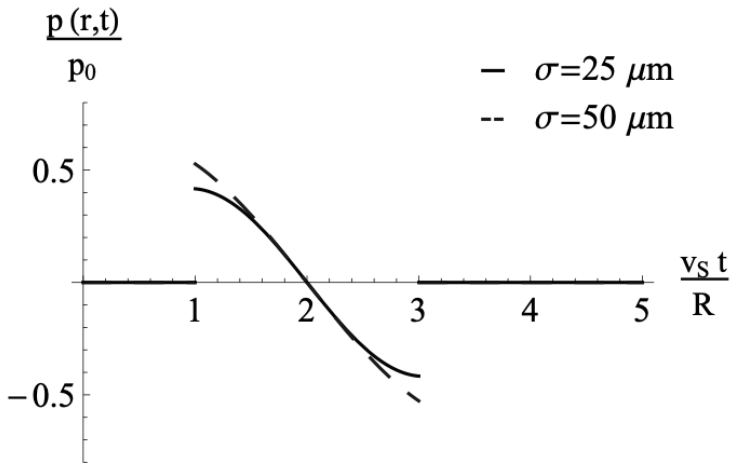

(b)

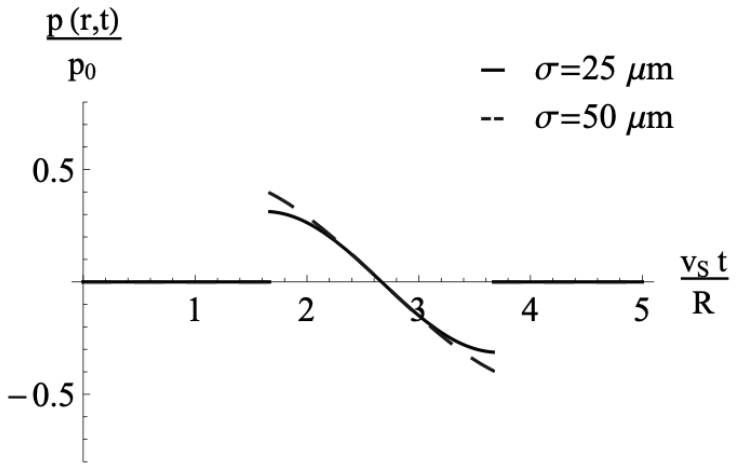

(c)

Figure 3. Normalized photoacoustic signal $p(r, t) / p_{0} v$ vs. normalized time $v_{s} t / R$ for beam-width values of $\sigma=25$ and $50 \mu \mathrm{m}$ at (a) $r=100 \mu \mathrm{m}$, (b) $r=150 \mu \mathrm{m}$, and (c) $r=200 \mu \mathrm{m}$, respectively where the radius of the absorber $R=75 \mu \mathrm{m}$, and the pulse dur ation $\tau=5 f_{s}$, respectively. 


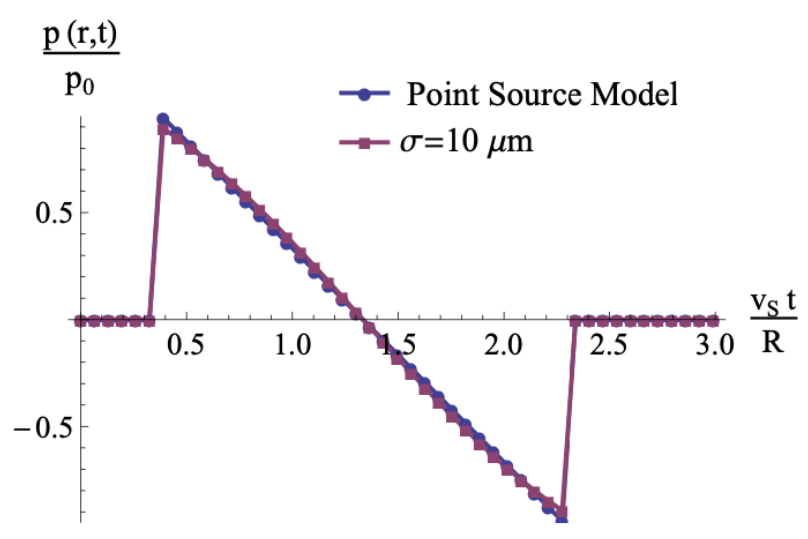

Figure 4. Normalized photoacoustic signal $p(r, t) / p_{0}$ vs. normalized time $v_{s} t / R$ at $r=100 \mu \mathrm{m}$ where the radius of the absorber $R=75 \mu \mathrm{m}$, the beam-width $\sigma=10 \mu \mathrm{m}$, and pulse duration $\tau=5$ ns. Here, circle and square represent the point source model and the model presented in this work, respectively.

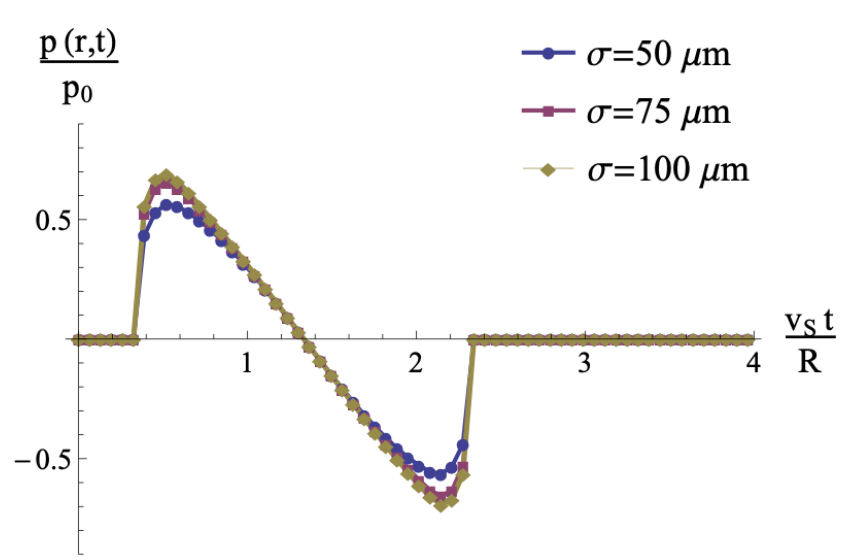

Figure 5. Normalized photoacoustic signal $p(r, t) / p_{0}$ vs. normalized time $v_{s} t / R$ at $r=100 \mu m$ for beam-width $\sigma=50,75$ and $100 \mu \mathrm{m}$ where the radius of the absorber $R=75 \mu \mathrm{m}$, and the pulse duration $\tau=5 \mathrm{~ns}$, respectively.

Figure 7 Normalized photoacoustic signal $p(r, t) / p_{0}$ vs. pulse duration $\tau$ at $r=100 \mu \mathrm{m}$ where the radius of the absorber $R=75$

\section{Conclusions and Recommendations}

The photoacoustic wave equation is solved analytically to describe the photoacoustic signal resulted from a sphericalshaped optically absorbing object which is heated up by a pulsed laser. The pulsed laser is represented by the product of the spatial term and the temporal term. The spatial term is modeled by a sampling function while the temporal term is described by a Gaussian function. The sampling function is used to model the spatial part of the source term because the experimental radial profile resulted from a spatial light modulator can be modeled accurately with a sampling function. Moreover, short pulsed lasers (such as nanosecond and femtosecond) generate nonlinear effects in tissue and they have a close-to-sinusoidal variation in the central pulse region, which enables the modeling of a sampling function. Moreover, the sampling modeling proposed in this work can be helpful for the understanding of the nonlinear

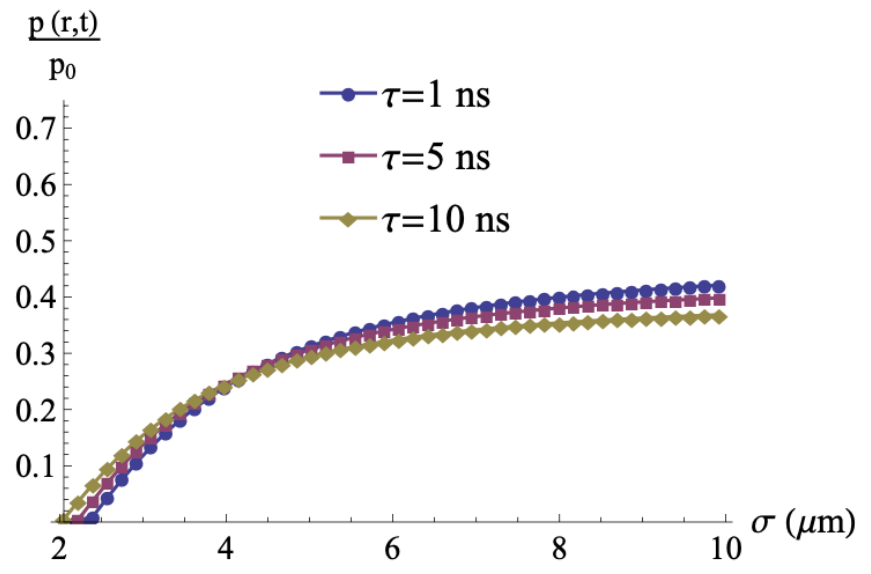

Figure 6. Normalized photoacoustic signal $p(r, t) / p_{0}$ vs. beamwidth $\sigma$ at $r=100 \mu m$ where the radius of the absorber $R=75$ $\mu \mathrm{m}$, circle, square, and diamond correspond to $\tau=1,5$, and 10 ns pulse duration values, respectively.

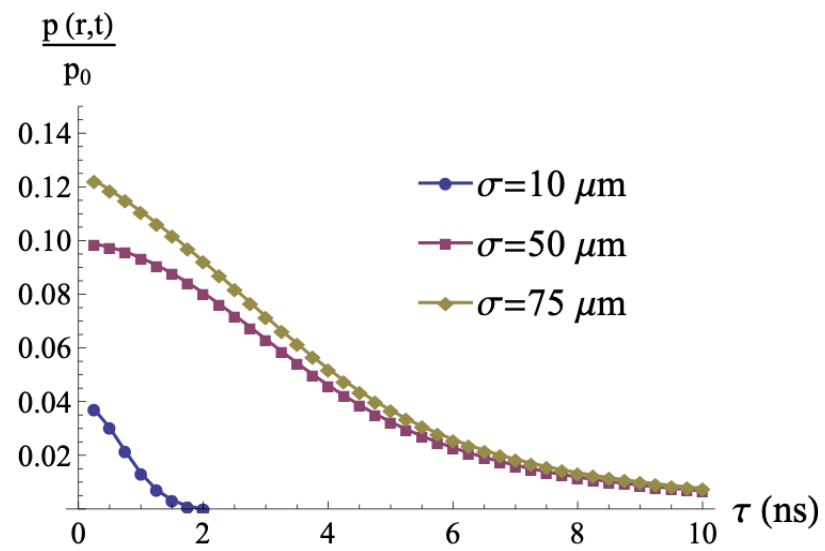

$\mu m$, circle, square, and diamond correspond to $\sigma=10,50$ and $75 \mu \mathrm{m}$ beam-width values, respectively.

mechanism in the field of photoacoustics. The Greens' function technique is implemented to find the frequency domain solutions after the Fourier transform is employed. The photoacoustic wave is also expressed in the time domain via the Inverse Fourier Transform. The time dependent wave expression includes laser factors (beam-width and pulse duration). The behaviour of the photoacoustic wave with respect to time is analyzed for various radial positions outside the absorber. The signal decreases with the radial position as expected. The analysis on how the laser factors affect the signal are also conducted. The signal diminishes as the beam-width decreases. If the beam-width is very small compared with the radius of the absorber, the sampling function behaves like a delta function (very sharp Gaussian) and the explicit observation of the effect of the beam-width on the signal disappears. The results presented by this work are in a very good agreement with the ones obtained by the delta function approach in the literature as the beam-width becomes very small. The beamwidth of the laser needs to be comparable with the radius of the 
spherical absorber for the photoacoustic wave expression to have an explicit beam-width dependency. The signal decreases with the pulse duration because the laser power is inversely proportional to the pulse duration. In addition to this, the photoacoustic wave equation will be no longer valid to describe the acoustic wave if the pulse duration is longer than the stress and the thermal relaxation times. Therefore, our model can be useful in biomedical applications since it enables to adjust laser factors.

\section{Acknowledge}

This research is supported by Boğaziçi University Research funding Grant No. BAP 15362.

\section{References}

Audo, F., Boscolo, S., Fatome, J., Kibler, B., \& Finot, C. (2017). "Nonlinear Spectrum Broadening Cancellation by Sinusoidal Phase Modulation." Optics Letters, 42(15), 2902-2905.

Bai, W., \& Diebold, G. J. (2018). "Moving Photoacoustic Sources: Acoustic Waveforms in One, Two, and Three Dimensions and Application to Trace Gas Detection." Physical Review E 125, 060902.

Beard, P. (2011). "Biomedical Photoacoustic Imaging." Interface Focus 1, 602-631.

Bell, A. G. (1880). "On the Production and Reproduction of Sound by Light." American Journal of Science 118, 305-324.

Calasso, I. G., Craig, W., \& Diebold, G. J. (2001). "Photoacoustic Point Source." Physical Review Letters 86, 3550-3.

Diebold, G. J., \& Westervelt, J. (1988). "The Photoacoustic Effect Generated by A Spherical Droplet in A Fluid." Journal of Acoustical Society of America 84, 2245.

Diebold, G. J., Sun, T., \& Khan, M. I. (1991). "Photoacoustic Monopole Radiation in One, Two, and Three Dimensions." Physical Review Letters 67, 3384-3387.

Gao, R., Xu, Z., Ren, Y., Song, L., \& Liu, C. (2021). "Nonlinear Mechanisms in photoacoustics: Powerful Tools in Photoacoustic Imaging." Photoacoustics, 100243.

Gusev, V., \& Chigarev, N. (2010). "Nonlinear Frequency-mixing Photoacoustic Imaging of A Crack: Theory." Journal of Applied Physics, 107(12), 124905.

Hoelen, C. G. A., de Mul, F. F. M., Pongers, R., \& Dekker, A. (1998). "Three-dimensional Photoacoustic Imaging of Blood Vessels in Tissue." Optics Letters 23, 648-650.

Hutchins, D., \& Tam, A. C. (1986). "Pulsed Photoacoustic Materials Characterization." IEEETransactions on Ultrasonics, Ferroelectrics, and Frequency Control 33, 429449.

Kozhushko, V., Khokhlova, T., Zharinov, A., Pelivanov, I., Solomatin, V., \& Karabutov, A. (2004). "Focused Array Transducer for Two-dimensional Optoacoustic Tomography." Journal of Acoustical Society of America 116, 1498.

Lai, H. M., \& Young, K. (1982). "Theory of the Pulsed Optoacoustic Technique." Journal of Acoustical Society of America 72, 2000.

Lin, L., Hu, P., Shi, J., Appleton, C. M., Maslov, K., Li, L., Zhang, R., \& Wang, L. V. (2018); "Single-breath-hold photoacoustic computed tomography of the breast." Nature Communications 9(1), 2352.

Morse, P. M., \& Feshbach, H. (1953). Methods of Theoretical Physics, Part I New York: McGraw- Hill.
Ripoll, R., \& Ntziachristos, N. (2005). "Quantitative Point Source Photoacoustic Inversion Formulas for Scattering and Absorbing Media." Physical Review E 71, 031912.

Sigrist, M. W., \& Kneubühl, F. K. (1978). "Laser-generated Stress Waves in Liquids." Journal of Acoustical Society of America 64, 1652.

Tabaru, T. E., Hayber, S. E., \& Saracoglu, O. G. (2018). "Frequency Domain Analysis of Laser and Acoustic Pressure Parameters in Photoacoustic Wave Equation for Acoustic Pressure Sensor Designs." Current Optics and Photonics 2, 250-260.

Tabaru, T. E., Hayber, S. E., Keser, S., \& Saracoglu, O. G. (2019). "Spectral Analysis for Photoacoustic Pressure Sensor Designs: Theoretical Model Improvement and Experimental Validation." Sensors and Actuators A: Physical 287, 76-83.

Tam, A. C. (1986). "Applications of Photoacoustic Sensing Techniques." Reviews of Modern Physics 58, 381-431.

Uluc, N., Unlu, M. B., Gulsen, G., \& Erkol, H. (2018). "Extended Photoacoustic Transport Model for Characterization of Red Blood Cell Morphology in Microchannel Flow." Biomedical Optics Express 9, 2785-2809.

Wang, L. V. (2004). “Ultrasound-mediated Biophotonic Imaging: A Review of Acousto-optical Tomography and Photoacoustic Tomography." Disease Markers 19, 123-38.

Wang, L. H., \& Wu, H. (2007). Biomedical Optics: Principles and Imaging. NJ: Wiley.

Wang, L. V. (2008). "Tutorial on Photoacoustic Microscopy and Computed Tomography." IEEE Journal of Selected Topics in Quantum Electronics 14, 171-179.

Wang, X., Pang, Y., Ku, G., Xie, X., Stoica, G., \& Wang, L. H. V. (2003). "Noninvasive Laser induced Photoacoustic Tomography for Structural and Functional in Vivo Imaging of the Brain." Nature Biotechnology 21, 803-806.

Wang, Y., Xie, X., Wang, X., Ku, G., Gill, K. L., O'Neal, D. P., Stoica, G., \& Wang, L. H. V. (2004). "Photoacoustic Tomography of a Nanoshell Contrast Agent in the in Vivo Rat Brain." Nano Letters 4, 1689-1692.

$\mathrm{Xu}$, M., \& Wang, L. V. (2006). "Photoacoustic imaging in biomedicine." Review of Scientific Instruments 77, 041101.

Zhang, J. M., Anastasio, A., Rivi_ere, P. J., \& Wang, L. H. (2009). "Effects of Different Imaging Models on Least-squares Image Reconstruction Accuracy in Photoacoustic Tomography." IEEE Transactions on Medical Imaging 28, 1781-1790. 